Jurnal Homepage: http:/journal2.um.ac.id/index.php/jaa (p-ISSN: 2087-9695; e-ISSN: 2580-1015)

\title{
Studi Corporate Information Transparency on the Internet (e-CTI) pada Bursa Efek Indonesia, Malaysia dan Singapura
}

\author{
Ruben Tanujaya ${ }^{1}$, Tarsisius Renald Suganda ${ }^{1}$, Dian Wijayanti ${ }^{1}$ \\ ${ }^{1}$ Universitas Ma Chung, Jl. Villa Puncak Tidar No. 1, Malang, Indonesia
}

\begin{abstract}
Diterima: 24 Februari
2020

Direvisi: 8 Mei 2020

Disetujui: 26 Mei 2020

\section{Koresponding:}

Ruben Tanujaya

rubentanujaya@gmail.com

DOI:

http://dx.doi.org/10.17977/

um004v7i22020p107
\end{abstract}

\begin{abstract}
The purpose of this study is to analyze the influence of macro and micro factors on e-CTI in countries as members of the IMS-GT. This research sample is 65 companies listed on the most liquid indexes on the three stock exchanges in 2017. The results of the study prove that the number of boards of directors has a positive effect on e-CTI. The large number of boards will increase boards' ability to encourage management in order to be more transparent. This is encouraged by the duties and responsibilities of the board of directors towards the stakeholders stated in the regulations of the three countries. The level of company disclosure in the three countries is identical. The case happened as a result of the existence of global competition between similar companies causing companies to compete with the aim of attracting investors.
\end{abstract}

Keywords: e-CTI; Macro Factors; Micro Factors

\begin{abstract}
Abstrak
Tujuan dari penelitian ini adalah untuk menganalisis pengaruh faktor makro dan mikro terhadap e-CTI di negara yang tergabung dalam IMS-GT. Sampel penelitian adalah 65 perusahaan yang terdaftar di indeks paling likuid pada ketiga bursa efek tahun 2017. Hasil penelitian membuktikan jika banyaknya dewan direksi ternyata berpengaruh positif pada e-CTI. Jumlah dewan direksi yang banyak akan meningkatkan kemampuan dewan direksi dalam mendorong manajemen untuk lebih transparan. Hal ini didorong dengan tugas dan tanggung jawab dewan direksi terhadap pemegang kepentingan yang tertera pada peraturan ketiga negara. Tingkat pengungkapan perusahaan di ketiga negara adalah indentik. Hal ini disebabkan karena adanya persaingan global antara perusahaan sejenis yang menyebabkan dorongan perusahaan untuk berkompetisi demi menarik minat investor.

Kata Kunci: e-CTI; Faktor Makro; Faktor Mikro
\end{abstract}

\section{PENDAHULUAN}

Chaudhuri \& Mukhopadhyay (2014) menyebutkan bahwa Foreign Direct Investment (FDI) adalah alat untuk melihat pertumbuhan ekonomi seluruh negara terutama di negara berkembang. Dengan adanya FDI yang melibatkan beberapa negara, maka perspektif investasi antar negara akan memberikan keuntungan bagi perusahaan-perusahaan pada negara terkait. Indonesia sebagai salah satu negara yang berada di kawasan Asia Tenggara menjadi negara tujuan investasi asing. Hal ini dapat dilihat dari jumlah investor asing terbesar di Indonesia yang merupakan investor dari Malaysia dan Singapura dengan jumlah FDI sebesar US\$6,885 miliar pada tahun 2017. Adanya hubungan kerjasama yang terjalin antara Indonesia, Malaysia, dan Singapura yang dikenal dengan perjanjian kerjasama IMS-GT (Indonesia, Malaysia Singapore - Growth Triangle) di tengah revolusi industri 4.0 ini menjadikan Malaysia dan Singapura sebagai investor asing terbesar di Indonesia.

FDI dipercaya dapat memberikan dampak positif bagi perekonomian makro maupun mikro (BKPM, 2017). Secara makro, perkembangan revolusi industri 4.0 yang menitikberatkan pada penggunaan media internet dipercaya mampu meningkatkan iklim investasi antar negara. Perusahaan dituntut untuk lebih transparan dalam menungkapkan informasi serta kondisi perusahaan agar dapat menarik investor asing dalam menanamkan modal. Corporate Information Transparency on the Internet (e-CTI) merupakan strategi jitu perusahaan dalam upaya mengungkapkan detail informasi perusahaan termasuk laporan keuangan melalui internet dengan harapan kepercayaan investor dapat meningkat khususnya di era revolusi industri 4.0 saat ini. Investasi asing yang masuk ke negara memberikan peluang bagi para investor untuk dapat berinvestasi. Investor terlebih dahulu melakukan 
analisis data makro suatu negara maupun data mikro perusahaan sebelum mengambil keputusan investasi. FDI mendorong perusahaan untuk lebih transparan dalam mengungkapkan informasi dan kondisi perusahaan sehingga investor lokal maupun asing tertarik untuk menanamkan modal.

Salah satu variabel makro yang dapat memengaruhi kualitas e-CTI adalah inflasi. Turrent \& Ariza (2012) berpendapat bahwa besarnya tingkat inflasi di suatu negara dapat memengaruhi praktik akuntansi yang diterapkan sehingga berdampak terhadap potensi penyimpangan Laporan Keuangan. Hal ini senada dengan yang diungkapkan oleh Anggraita \& Syafiqurrahman (2013) yang menyatakan inflasi menyebabkan tujuan pelaporan keuangan tidak relevan. Beberapa penelitian telah dilakukan untuk membuktikan pengaruh inflasi terhadap e-CTI. Anggraita \& Syafiqurrahman (2013) membuktikan bahwa inflasi berpengaruh positif terhadap e-CTI, namun Turrent \& Ariza (2012) membuktikan bahwa inflasi berpengaruh negatif terhadap e-CTI, sedangkan Wiwin (2017) membuktikan bahwa inflasi tidak berpengaruh terhadap e-CTI.

Faktor makro lain yang dapat memengaruhi e-CTI adalah perkembangan ekonomi. Perkembangan ekonomi di suatu negara memengaruhi cara perusahaan berkomunikasi dengan para investor (Archambault \& Archambault, 2003). Samaha \& Abdallah (2011) menyatakan bahwa pengungkapan informasi perusahaan di internet pada negara yang perekonomian dan pasar modal berkembang lebih rendah dibandingkan dengan negara dengan perekonomian dan pasar modal yang maju dan telah bertumbuh secara sempurna. Penelitian Turrent \& Ariza (2012) serta Anggraita \& Syafiqurrahman (2013) membuktikan bahwa perkembangan ekonomi berpengaruh positif terhadap e-CTI. Berbeda dengan kedua penelitian tersebut, Wiwin (2017) membuktikan bahwa perkembangan ekonomi tidak berpengaruh terhadap e-CTI.

Mekanisme hukum merupakan salah satu variabel makro lain yang dapat memengaruhi e-CTI. Campbell (2006) memaparkan bahwa perusahaan yang beroperasi pada situasi dan kondisi dengan tekanan tinggi serta mekanisme hukum yang lebih memihak pada stakeholders membuat perusahaan memiliki rasa tanggung jawab dan transparansi yang lebih baik untuk memberikan informasi perusahaan kepada stakeholders. Turrent \& Ariza (2012) dan Anggraita \& Syafiqurrahman (2013) membuktikan bahwa mekanisme hukum berpengaruh positif terhadap e-CTI. Ojah \& Mokoteli (2012) membuktikan bahwa mekanisme hukum berpengaruh negatif terhadap e-CTI. Berbeda dengan kedua penelitian tersebut, Wiwin (2017) membuktikan mekanisme hukum tidak berpengaruh terhadap e-CTI.

Variabel makro yang terakhir adalah faktor budaya. Askary, et al. (2008) berpendapat bahwa praktik akuntansi dipengaruhi oleh faktor budaya dalam suatu negara seperti nilai-nilai, agama, dan politik. Oleh karena itu, akuntansi dan praktik akuntansi berbeda di setiap negara dengan budaya yang berbeda. Informasi yang diungkapkan oleh perusahaan melalui internet berbeda-beda tergantung budaya negara tempat perusahaan berdiri (Bonson \& Escobar, 2002). Jaggi \& Low (2000) mengatakan bahwa nilai-nilai budaya mempunyai dampak signifikan dalam pengungkapan Laporan Keuangan perusahaan di negara-negara common law. Penelitian Anggraita \& Syafiqurrahman (2013) membuktikan bahwa budaya berpengaruh negatif terhadap e-CTI, namun Jaggi \& Low (2000) membuktikan bahwa budaya tidak berpengaruh terhadap e-CTI.

Variabel mikro yang dapat mempengaruhi e-CTI adalah ukuran dewan direksi. Perusahaan yang memiliki dewan direksi yang banyak dapat meningkatkan pengendalian internal perusahaan serta mendorong manajemen untuk lebih transparan (Nurfadilah \& Sagara, 2015). Akhtaruddin, et al. (2009), Abdillah (2015), dan Wiwin (2017) membuktikan bahwa ukuran dewan direksi berpengaruh positif terhadap e-CTI, namun Erer \& Dalgic (2011), dan Anggraita \& Syafiqurrahman (2013) membuktikan bahwa ukuran dewan direksi tidak berpengaruh terhadap e-CTI.

Faktor mikro lain yang mempengaruhi e-CTI adalah proporsi direktur independen. Elfeky (2017) menyatakan bahwa dengan banyaknya proporsi direktur independen dalam suatu perusahaan dapat mendorong manajemen dalam mengungkapkan informasi secara sukarela. Akhtaruddin, et al. (2009), Erer \& Dalgic (2011), dan Abdillah (2015) membuktikan bahwa proporsi direktur independen berpengaruh positif terhadap e-CTI. Namun Anggraita \& Syafiqurrahman (2013), dan Wiwin (2017) membuktikan bahwa proporsi direktur independen tidak berpengaruh terhadap e-CTI.

Faktor mikro terakhir yang dapat memengaruhi e-CTI adalah pemusatan kepemilikan. Pada perusahaan dengan struktur kepemilikan yang menyebar, potensi terjadinya perbedaan kepentingan antara investor mayoritas dengan investor minoritas meningkat. Peningkatan ini merupakan pendorong perusahaan untuk mengungkapkan informasi yang lebih banyak dengan tujuan membantu pemegang saham dalam memantau dan mengendalikan manajemen, serta untuk menunjukkan nilai perusahaan (Ousama \& Fatimah, 2010). Ojah \& Mokoteli (2012) dan Turrent \& Ariza (2012) membuktikan bahwa pemusatan kepemilikan berpengaruh negatif terhadap e-CTI. Namun, Anggraita \& Syafiqurrahman (2013) dan Wiwin (2017) membuktikan bahwa pemusatan kepemilikan tidak berpengaruh terhadap e-CTI. 
Wiwin (2017) menyatakan bahwa berdasarkan perkembangan e-CTI di negara-negara ASEAN, tingkat pengungkapan informasi di masing-masing pasar saham di negara ASEAN sama. Hal ini dibuktikan dengan tingkat pengungkapan e-CTI yang tidak berbeda secara signifikan di Indonesia, Malaysia, dan Singapura.

Penelitian ini bertujuan untuk menginvestigasi lebih lanjut tentang pengaruh variabel makro dan mikro terhadap tingkat e-CTI di negara yang tergabung dalam IMS-GT. Perbedaan penelitian ini dengan penelitian Turrent \& Ariza (2012) adalah penelitian sebelumnya tidak mencari perbedaan tingkat e-CTI, sedangkan penelitian ini mencari perbedaan tingkat e-CTI dengan menggunakan data terbaru. Pemilihan variabel kontrol dalam penelitian ini sesuai dengan penelitian dari Turrent \& Ariza (2012). Alasan penggunaan variabel kontrol ukuran perusahaan, jenis industri manufaktur, profitabilitas dan leverage adalah untuk mengendalikan variabel lain yang berpotensi berpengaruh terhadap e-CTI sehingga hasil penelitian lebih optimal menjelaskan fenomena penelitian. Berdasarkan latar belakang tersebut, hipotesis yang diambil adalah sebagai berikut:

$\mathrm{H}_{1}$ : Inflasi berpengaruh positif terhadap e-CTI.

$\mathrm{H}_{2}$ : Perkembangan ekonomi berpengaruh positif terhadap e-CTI.

$\mathrm{H}_{3}^{2}$ : Mekanisme hukum berpengaruh positif terhadap e-CTI.

$\mathrm{H}_{4}^{3}$ : Budaya berpengaruh negatif terhadap e-CTI.

$\mathrm{H}_{5}^{4}$ : Ukuran dewan direksi berpengaruh positif terhadap e-CTI.

$\mathrm{H}_{6}^{5}$ : Proporsi direktur independen berpengaruh positif terhadap e-CTI.

$\mathrm{H}_{7}^{6}$ : Pemusatan kepemilikan berpengaruh negatif terhadap e-CTI.

$\mathrm{H}_{8}$ : Ketiga rata-rata e-CTI Indonesia, Malaysia dan Singapura identik

\section{METODE}

Variabel dependen dalam penelitian ini adalah Corporate Information Transparency on the Internet (e-CTI). Variabel e-CTI diukur berdasarkan indeks e-CTI yang mengacu pada indeks yang digunakan dalam penelitian Wiwin (2017). Pengukuran nilai e-CTI menggunakan variabel dummy. Setiap butir pernyataan yang diungkapkan dalam website perusahaan diberi nilai 1, sedangkan yang tidak diungkapkan dalam website diberi nilai 0 . Kemudian, jumlah nilai yang diperoleh dibagi dengan jumlah butir pernyataan pada indeks pengukuran e-CTI. Variabel independen dalam penelitian terdiri dari tujuh variabel yang terbagi dalam empat variabel makro dan tiga variabel mikro. Variabel makro yang digunakan adalah inflasi, perkembagan ekonomi, mekanisme hukum dan budaya. Inflasi diukur dengan nilai rata-rata inflasi tahunan yang diperoleh melalui laman World Bank. Perkembangan ekonomi menggunakan tingkat Gross Domestic Product(GDP) per kapita yang diperoleh melalui laman World Bank. Mekanisme hukum diukur menggunakan rata-rata kriteria yang terdapat di indeks Worldwide Governance Indicator (WGI) yang diperoleh melalui laman World Bank. Budaya diukur menggunakan nilai rata-rata kriteria yang ada pada indeks budaya yang dikembangkan oleh Hofstede, et al. (2010).

Variabel mikro yang digunakan dalam penelitian ini adalah ukuran dewan direksi, proporsi direktur independen dan pemusatan kepemilikan. Ukuran dewan direksi diukur menggunakan jumlah dewan direksi yang terdapat dalam laporan tahunan perusahaan. Proporsi direktur independen diukur dengan menghitung jumlah direktur independen dibagi dengan jumlah keseluruhan direksi. Pemusatan kepemilikan diukur dengan rata-rata persentase saham biasa yang dimiliki oleh pemegang saham mayoritas yang memiliki persentase saham lebih dari 5\%. Variabel kontrol yang digunakan dalam penelitian ini adalah ukuran perusahaan, jenis industri, profitabilitas dan leverage. Ukuran perusahaan diukur menggunakan logaritma natural (Ln) dari total aset. Jenis industri diukur menggunakan variabel dummy yaitu perusahaan yang bergerak di sektor manufaktur diberi nilai 1, selain itu diberi nilai 0. Profitabilitas dihitung dengan rumus Return on Assets. Leverage dihitung dengan rumus Debt to Equity Ratio (DER).

Populasi penelitian ini adalah seluruh perusahaan yang terdaftar di indeks saham LQ45 sejumlah 45 perusahaan (Bursa Efek Indonesia), Kuala Lumpur Composite Index (KLCI) berjumlah 30 perusahaan (Bursa Efek Malaysia) dan Singapore Transparency Index (STI) berjumlah 30 perusahaan (Bursa Efek Singapura). Teknik sampel dalam penelitian ini adalah purposive sampling dengan kriteria: 1) terdaftar di Bursa Efek Indonesia, Malaysia, dan Singapura secara konsisten; 2) memiliki website yang dapat diakses; 3) menerbitkan Laporan Keuangan yang berakhir 31 Desember 2017; dan 4) Laporan Keuangan menggunakan mata uang resmi negara. Tabel 1 berikut ini menunjukkan hasil dari purposive sampling. 
Tabel 1. Sampel Penelitian

\begin{tabular}{|c|c|c|c|}
\hline \multirow{2}{*}{ Kriteria } & \multicolumn{3}{|c|}{ Jumlah Perusahaan } \\
\hline & Indonesia & Malaysia & Singapura \\
\hline $\begin{array}{l}\text { Perusahaan yang terdaftar dalam } \\
\text { indeks saham paling likuid }\end{array}$ & 45 & 30 & 30 \\
\hline $\begin{array}{l}\text { Perusahaan yang terdaftar dalam } \\
\text { indeks saham paling likuid secara } \\
\text { tidak konsisten }\end{array}$ & (5) & (1) & (3) \\
\hline $\begin{array}{l}\text { Perusahaan dengan website yang } \\
\text { tidak dapat diakses }\end{array}$ & 0 & 0 & $(1)$ \\
\hline $\begin{array}{l}\text { Perusahaan yang memiliki Lapo- } \\
\text { ran Keuangan tidak lengkap }\end{array}$ & $(1)$ & 0 & 0 \\
\hline $\begin{array}{l}\text { Perusahaan yang memiliki Lapo- } \\
\text { ran Keuangan tidak berakhir } 31 \\
\text { Desember } 2017\end{array}$ & 0 & $(11)$ & $(7)$ \\
\hline $\begin{array}{l}\text { Perusahaan yang mata uang pel- } \\
\text { aporan bukan uang resmi Negara }\end{array}$ & (4) & 0 & $(7)$ \\
\hline Jumlah Sampel & 35 & 18 & 12 \\
\hline
\end{tabular}

Penelitian ini menggunakan data kuantitatif. Data kuantitatif yang digunakan dalam penelitian adalah Laporan Keuangan yang memenuhi kriteria pemilihan sampel, nilai WGI, tingkat GDP per kapita, tingkat inflasi tahunan, struktur perusahaan dan indeks budaya Geert Hofstede. Sumber data dalam penelitian ini adalah data sekunder. Data sekunder dalam penelitian ini diperoleh dari laporan keuangan, website perusahaan, website World Bank dan website Geert Hofstede.

Penelitian ini menggunakan pengujian statistik deskriptif, uji asumsi klasik dan regresi linear berganda untuk melihat pengaruh variabel independen terhadap variabel dependen. Untuk menguji perbedaan tingkat e-CTI, penelitian ini menggunakan uji One Way Anova. Berikut adalah model regresi dalam penelitian ini:

$$
\mathrm{e}-\mathrm{CTI}=\alpha+\beta_{1} \mathrm{INF}+\beta_{2} \mathrm{GDP}+\beta_{3} \mathrm{WGI}+\beta_{4} \mathrm{FB}+\beta_{5} \mathrm{TD}+\beta_{6} \mathrm{DI}+\beta_{7} \mathrm{PK}+\mathrm{e}
$$

Keterangan:

$\begin{array}{ll}\text { e-CTI } & : \text { Corporate Information Transparency on the Internet } \\ \text { INF } & : \text { Inflasi } \\ \text { GDP } & : \text { Perkembangan Ekonomi } \\ \text { WGI } & : \text { Mekanisme Hukum } \\ \text { FB } & : \text { Faktor Budaya } \\ \text { TD } & : \text { Ukuran Dewan Direksi } \\ \text { DI } & : \text { Proporsi Direktur Independen } \\ \text { PK } & : \text { Pemusatan Kepemilikan } \\ \alpha, \beta & : \text { Konstanta } \\ \text { e } & : \text { Komponen dalam model / error }\end{array}$

\section{HASIL DAN PEMBAHASAN}

\section{Analisis Data Deskriptif}

Statistik deskriptif dalam penelitian ini terdiri dari perusahaan yang terdaftar di bursa efek Indonesia (LQ45), Malaysia (KLCI) dan Singapura (STI). Berikut adalah hasil statistik deskriptif dalam penelitian ini dapat dilihat pada Tabel 2, 3, dan 4 .

Dari Tabel statistik deskriptif 2 , 3, dan 4 dapat disimpulkan bahwa rata-rata tingkat e-CTI tertinggi dimiliki oleh Indonesia dan Singapura. Inflasi tertinggi dimiliki oleh Indonesia, sedangkan perkembangan ekonomi dan mekanisme hukum di Singapura merupakan yang tertinggi dibandingkan Indonesia dan Malaysia. Faktor budaya tertinggi dimiliki oleh Malaysia. Ukuran dewan direksi dan proporsi direktur independen di Singapura lebih tinggi dibandingkan Indonesia dan Malaysia. Pemusatan kepemilikan tertinggi adalah Indonesia. 
Tabel 2. Statistik Deskriptif LQ45 (Indonesia)

\begin{tabular}{lccccc}
\hline \multicolumn{1}{c}{ Variabel } & N & Minimum & Maximum & Mean & Standard Deviation \\
\hline eCTI & 35 &, 694 &, 861 &, 785 &, 041 \\
Inflasi & 35 & 3,809 & 3,809 & 3,809 &, 000 \\
Perkembangan Ekonomi & 35 & 3846,860 & 3846,860 & 3846,860 &, 000 \\
Mekanisme Hukum & 35 &,- 175 &,- 175 &,- 175 &, 000 \\
Faktor Budaya & 35 & 47,667 & 47,667 & 47,667 &, 000 \\
Ukuran Dewan Direksi & 35 & 4 & 11 & 7,49 & 1,976 \\
Proporsi Direktur Independen & 35 &, 000 &, 200 &, 079 &, 077 \\
Pemusatan Kepemilikan & 35 &, 095 &, 850 &, 495 &, 209 \\
\hline
\end{tabular}

Tabel 3. Statistik Deskriptif KLCI (Malaysia)

\begin{tabular}{lccccc}
\hline \multicolumn{1}{c}{ Variabel } & N & Minimum & Maximum & Mean & Standard Deviation \\
\hline eCTI & 18 &, 639 &, 833 &, 781 &, 055 \\
Inflasi & 18 & 3,792 & 3,792 & 3,792 &, 000 \\
Perkembangan Ekonomi & 18 & 9951,540 & 9951,540 & 9951,540 &, 000 \\
Mekanisme Hukum & 18 &, 287 &, 287 &, 287 &, 000 \\
Faktor Budaya & 18 & 51,667 & 51,667 & 51,667 &, 000 \\
Ukuran Dewan Direksi & 18 & 7 & 13 & 9,28 & 2,024 \\
Proporsi Direktur Independen & 18 &, 333 &, 727 &, 517 &, 108 \\
Pemusatan Kepemilikan & 18 &, 105 &, 699 &, 259 &, 147 \\
\hline
\end{tabular}

Tabel 4. Statistik Deskriptif STI (Singapura)

\begin{tabular}{lccccc}
\hline \multicolumn{1}{c}{ Variabel } & N & Minimum & Maximum & Mean & Standard Deviation \\
\hline eCTI & 12 &, 667 &, 833 &, 785 &, 050 \\
Inflasi & 12 &, 592 &, 592 &, 592 &, 000 \\
Perkembangan Ekonomi & 12 & 57714,300 & 57714,300 & 57714,300 &, 000 \\
Mekanisme Hukum & 12 & 1,617 & 1,617 & 1,617 &, 000 \\
Faktor Budaya & 12 & 44,667 & 44,667 & 44,66700 &, 000 \\
Ukuran Dewan Direksi & 12 & 6 & 13 & 9,92 & 2,151 \\
Proporsi Direktur Independen & 12 &, 400 &, 917 &, 692 &, 150 \\
Pemusatan Kepemilikan & 12 &, 099 &, 239 &, 152 &, 049 \\
\hline
\end{tabular}

\section{Uji Koefisien Korelasi}

Tabel 5 menunjukkan korelasi antara variabel dependent (e-CTI) dan variabel independen. Berdasarkan Tabel 5 dapat dilihat bahwa terdapat korelasi yang sangat kuat antara ketiga variabel independen dalam penelitian ini yaitu inflasi (INF), perkembangan ekonomi (GDP) dan mekanisme hukum (WGI). Hal ini dapat menyebabkan masalah multikolinearitas dalam model (Turrent \& Ariza, 2012). Untuk mencegah terjadinya multikolinearitas, maka dilakukan analisis terpisah antara ketiga variabel yang memiliki korelasi kuat.

Dari Tabel 5 dapat dilihat bahwa variabel independen inflasi (INF), perkembangan ekonomi (GDP) dan mekanisme hukum (WGI) memiliki korelasi yang sangat kuat. Oleh sebab itu, dilakukan analisis terpisah untuk mencegah terjadi masalah multikolinearitas. Berikut adalah model penelitian baru yang digunakan:

1. Model 1 (Inflasi)

Model regresi pertama pada penelitian ini adalah sebagai berikut.

$\mathrm{e}-\mathrm{CTI}=\alpha+\beta_{1} \mathrm{INF}+\beta_{2} \mathrm{FB}+\beta_{3} \mathrm{TD}+\beta_{4} \mathrm{DI}+\beta_{5} \mathrm{PK}+\mathrm{e}$ 
2. Model 2 (Perkembangan Ekonomi)

Model regresi kedua pada penelitian ini adalah sebagai berikut.

$\mathrm{e}-\mathrm{CTI}=\alpha+\beta_{1} \mathrm{GDP}+\beta_{2} \mathrm{FB}+\beta_{3} \mathrm{TD}+\beta_{4} \mathrm{DI}+\beta_{5} \mathrm{PK}+\mathrm{e}$

3. Model 3 (Mekanisme Hukum)

Model regresi ketiga pada penelitian ini adalah sebagai berikut.

$\mathrm{e}-\mathrm{CTI}=\alpha+\beta_{1} \mathrm{WGI}+\beta_{2} \mathrm{FB}+\beta_{3} \mathrm{TD}+\beta_{4} \mathrm{DI}+\beta_{5} \mathrm{PK}+\mathrm{e}$

\section{Uji Asumsi Klasik}

Uji asumsi klasik yang dilakukan dalam penelitian ini adalah uji normalitas, uji multikolinearitas dan uji heteroskedastisitas. Uji normalitas dalam penelitian ini menggunakan data asli dari nilai variabel yang tidak diubah. Hasil uji normalitas tidak lolos. Hal yang sama terjadi pada saat data ditransformasi absolute, logaritma dan logaritma natural namun masih tetap tidak lolos. Sehubungan dengan itu, maka dilakukan uji normalitas gabungan pada unstandardized residual.

Tabel 6 menunjukkan bahwa nilai Asymp. Sig. (2-tailed) sebesar 0,364. Oleh karena nilai lebih besar dari 0,05 , maka data dalam model regresi ini telah berdistribusi normal sehingga bisa dilanjutkan ke uji berikutnya. Uji multikolineartias dalam penelitian ini dilakukan secara terpisah dengan 3 model penelitian.

Tabel 5. Uji Korelasi Pearson

\begin{tabular}{ccccccccc}
\hline Variabel & e-CTI & WGI & GDP & INF & TD & DI & PK & FB \\
\hline e-CTI & 1 & & & & & & & \\
WGI &,- 009 & 1 & & & & & & \\
GDP &,- 017 &, $988^{* *}$ & 1 & & & & & \\
INF &,- 004 &,$- 967^{* *}$ & $-917^{* *}$ & 1 & & & & \\
TD &, $272^{*}$ &, $385^{*}$ &, $421^{* *}$ &,$- 305^{*}$ & 1 & & & \\
DI &, 153 &, $310^{*}$ &, $327^{* *}$ &,$- 267^{* *}$ &, 075 & 1 & & \\
PK &, 111 &,$- 572^{* *}$ &,$- 603^{* *}$ &, $490^{* *}$ &,- 153 &,- 154 & 1 & \\
FB &,- 039 &,$- 518^{* *}$ &,$- 380^{* *}$ &, $718^{* *}$ &, 028 &,- 049 &, 084 & 1 \\
\hline
\end{tabular}

Tabel 6. Uji Normalitas

\begin{tabular}{cc}
\hline Variabel & Asymp. Sig. (2-tailed) \\
\hline Unstadardized Residual &, 364 \\
\hline
\end{tabular}

Tabel 7. Uji Multikolinearitas Model 1

\begin{tabular}{lcc}
\hline \multicolumn{1}{c}{ Variabel } & Tolerance & VIF \\
\hline Inflasi &, 206 & 4,850 \\
Faktor Budaya &, 304 & 3,295 \\
Ukuran Dewan Direksi &, 743 & 1,346 \\
Proporsi Direktur Independen &, 870 & 1,149 \\
Pemusatan Kepemilikan &, 583 & 1,714 \\
\hline
\end{tabular}

Tabel 8. Uji Multikolinearitas Model 2

\begin{tabular}{lrc}
\hline \multicolumn{1}{c}{ Variabel } & Tolerance & VIF \\
\hline Perkembangan Ekonomi &, 364 & 2,746 \\
Faktor Budaya &, 755 & 1,324 \\
Ukuran Dewan Direksi &, 743 & 1,346 \\
Proporsi Direktur Independen &, 870 & 1,149 \\
Pemusatan Kepemilikan &, 583 & 1,714 \\
\hline
\end{tabular}


Tabel 9. Uji Multikolinearitas Model 3

\begin{tabular}{lcc}
\hline \multicolumn{1}{c}{ Variabel } & Tolerance & VIF \\
\hline Mekanisme Hukum &, 311 & 3,211 \\
Faktor Budaya &, 573 & 1,747 \\
Ukuran Dewan Direksi &, 743 & 1,346 \\
Proporsi Direktur Independen &, 870 & 1,149 \\
Pemusatan Kepemilikan &, 583 & 1,714 \\
\hline
\end{tabular}

Tabel 10. Uji Heteroskedastisitas Model 1

\begin{tabular}{lc}
\hline \multicolumn{1}{c}{ Variabel } & Sig. \\
\hline Inflasi &, 395 \\
Faktor Budaya &, 225 \\
Ukuran Dewan Direksi &, 430 \\
Proporsi Direktur Independen &, 130 \\
Pemusatan Kepemilikan &, 196 \\
\hline
\end{tabular}

Tabel 11. Uji Heteroskedastisitas Model 2

\begin{tabular}{lc}
\hline \multicolumn{1}{c}{ Variabel } & Sig. \\
\hline Perkembangan Ekonomi &, 395 \\
Faktor Budaya &, 225 \\
Ukuran Dewan Direksi &, 430 \\
Proporsi Direktur Independen &, 130 \\
Pemusatan Kepemilikan &, 196 \\
\hline
\end{tabular}

Tabel 12. Uji Heteroskedastisitas Model 3

\begin{tabular}{lc}
\hline \multicolumn{1}{c}{ Variabel } & Sig. \\
\hline Mekanisme Hukum &, 395 \\
Faktor Budaya &, 212 \\
Ukuran Dewan Direksi &, 430 \\
Proporsi Direktur Independen &, 130 \\
Pemusatan Kepemilikan &, 196 \\
\hline
\end{tabular}

Dari Tabel 7, 8 dan 9 secara berturut-turut dapat dilihat bahwa nilai tolerance dari ketiga model tidak melebihi 1 sedangkan VIF tidak melebihi 10 atau lebih kecil dari 10 sehingga ketiga model bebas dari masalah multikolinearitas. Proses berikutnya adalah uji heteroskedastisitas dengan hasil uji pada Tabel 10, 11, dan 12 .

Dari tabel 10, 11 dan 12 secara berturut-turut dapat dilihat bahwa ketiga model memiliki nilai signifikansi lebih besar dari 0,05. Oleh karena itu, seluruh variabel tidak mengalami heteroskedastisitas. Berdasarkan hasil uji asumsi klasik tersebut, maka dapat disimpulkan bahwa model penelitian layak untuk dilakukan uji regresi linear berganda.

\section{Uji Regresi Linear Berganda}

Variabel kontrol yang digunakan dalam penelitian ini yaitu ukuran perusahaan, jenis industri, profitabilitas dan leverage terbukti tidak signifikan. Hal ini sudah dilakukan peneliti sebagai upaya untuk mereduksi bias namun hasil memang tidak signifikan (Harsono, 2002). Oleh karena itu, pengujian hipotesis tetap dilakukan dengan hasil dapat dilihat pada Tabel 13.

\section{Pengaruh Inflasi terhadap e-CTI}

Hasil pengujian membuktikan bahwa inflasi tidak memiliki pengaruh pada e-CTI sehingga $\mathrm{H}_{1}$ ditolak. Hasil penelitian ini sama dengan penelitian Wiwin (2017). Penelitian yang dilakukan oleh Nur (2012) menunjukkan bahwa tingkat konsumsi dipengaruhi oleh inflasi. Pada saat inflasi, 
Tabel 13. Uji Regresi Linear Berganda

\begin{tabular}{|c|c|c|c|c|c|c|}
\hline \multirow{2}{*}{ Variabel } & \multicolumn{2}{|c|}{ Model 1} & \multicolumn{2}{|c|}{ Model 2} & \multicolumn{2}{|c|}{ Model 3} \\
\hline & Sig. & Coeff. Beta & Sig. & Coeff. Beta & Sig. & Coeff. Beta \\
\hline Inflasi & ,307 & ,652 & & & & \\
\hline Perkembangan Ekonomi & & & ,307 &,- 491 & & \\
\hline Mekanisme Hukum & & & & & ,307 &,- 531 \\
\hline Faktor Budaya & ,304 &,- 487 & ,350 &,- 205 & ,320 &,- 294 \\
\hline Ukuran Dewan Direksi &, 026 & ,347 & ,026 & ,347 & ,026 & ,347 \\
\hline $\begin{array}{l}\text { Proporsi Direktur Indepen- } \\
\text { den }\end{array}$ &, 218 &, 173 & ,218 &, 173 & ,218 & ,173 \\
\hline Pemusatan Kepemilikan &, 562 & ,097 &, 562 &, 097 &, 562 &, 097 \\
\hline
\end{tabular}

harga barang \& jasa meningkat yang menyebabkan daya beli masyarakat menurun. Sebaliknya, harga barang \& jasa menurun sehingga daya beli masyarakat meningkat ketika tingkat inflasi rendah. Boediono (1985) mengatakan bahwa inflasi terbagi atas em[at jenis yaitu inflasi ringan, inflasi sedang, inflasi berat dan inflasi sangat berat. Inflasi ringan tidak begitu menganggu keadaan perekonomian karena harga barang hanya mengalami kenaikan secara umum. Nilai Inflasi ringan di bawah $10 \%$. Berdasarkan hasil analisis data deskriptif, dapat dilihat bahwa ketiga negara memiliki tingkat inflasi kurang dari 5\% yaitu Indonesia sebesar 3,8\%, Malaysia sebesar 3,7\% dan Singapura sebesar 0,5\%. Hal ini menunjukkan bahwa masyarakat lebih memilih untuk meningkatkan konsumsi barang dan jasa dibandingkan melakukan investasi. Minat investasi masyarakat yang rendah menyebabkan rendahnya motivasi manajemen untuk memberikan informasi-informasi lain perusahaan melalui e-CTI. Perbedaan hasil penelitian ini dengan penelitian Wiwin (2017) adalah sampel penelitian yang dilakukan pada tiga negara yang memiliki kerjasama ekonomi IMS-GT dan penggunaan tahun yang lebih baru dibandingkan penelitian Wiwin (2017). Selain itu, hasil penelitian juga menunjukkan bahwa terdapat perbedaan tingkat inflasi Indonesia, Malaysia dan Singapura.

\section{Pengaruh Perkembangan Ekonomi terhadap e-CTI}

Hasil pengujian menunjukkan bahwa perkembangan ekonomi tidak berpengaruh pada e-CTI sehingga $\mathrm{H}_{2}$ ditolak. Hasil penelitian ini sama dengan penelitian Wiwin (2017). Kewal (2012) meyatakan bahwa peningkatan GDP per kapita mengindikasikan peningkatan kesejahteraan masyarakat suatu negara. Indonesia, Malaysia dan Singapura tergolong negara dengan perekonomian yang masih berkembang (Idris, 2020), sehingga peningkatan GDP per kapita membuat masyarakat cenderung memilih untuk meningkatkan konsumsi terhadap barang dan jasa. Oleh karena itu, peningkatan GDP per kapita tidak mempengaruhi pola investasi di pasar modal sehingga tidak mendorong perusahaan untuk meningkatkan pengungkapan informasi guna menarik minat investor. Hasil penelitian yang menunjukkan perkembangan ekonomi tidak berpengaruh terhadap e-CTI disebabkan karena masyarakat di ketiga negara lebih memilih untuk meningkatkan konsumsi terhadap barang dan jasa sehingga tidak berpengaruh terhadap nilai investasi dan GDP. Peningkatan GDP yang tidak terjadi di suatu negara tidak memberikan peluang bagi perusahaan untuk menarik minat investor melalui e-CTI. Perbedaan penelitian ini dengan penelitian Wiwin (2017) adalah kebaruan data. Disamping itu, penelitian Wiwin (2017) menunjukkan terjadi peningkatan GDP per kapita dari ketiga negara dalam penelitian ini yaitu Indonesia, Malaysia dan Singapura. GDP per kapita Indonesia sebesar 3.346,487 pada tahun 2015 menjadi 3.846,860 di tahun 2017, sedangkan Malaysia dari sebesar 9.768,327 pada tahun 2015 menjadi 9.951,540 di tahun 2017. Singapura memiliki kenaikan GDP dari sebesar 52.888,745 di tahun 2015 menjadi $57.714,300$.

\section{Pengaruh Mekanisme Hukum terhadap e-CTI}

Hasil pengujian membuktikan mekanisme hukum tidak berpengaruh pada e-CTI sehingga $\mathrm{H}_{3}$ ditolak. Hasil penelitian ini sama dengan penelitian Ojah \& Mokoteli (2012). Indonesia, Malaysia dan Singapura menganut sistem hukum common law sehingga cenderung berorientasi pada kepentingan shareholder. Perusahaan-perusahaan di negara common law cenderung mengutamakan informasi keuangan dan mengesampingkan informasi non-keuangan (Holthausen, 2009). Padahal dalam pengambilan keputusan, investor tidak hanya memperhatikan informasi keuangan saja namun juga membutuhkan informasi lain seperti informasi non-keuangan. Orientasi mekanisme hukum common law di ketiga negara hanya pada informasi keuangan saja sehingga mekanisme hukum tidak 
berpengaruh pada e-CTI. e-CTI merupakan transparansi perusahaan berupa penyajian informasi lain di luar informasi keuangan. Perbedaan penelitian ini dengan penelitian Ojah \& Mokoteli (2012) adalah pengambilan sampel pada 44 perusahaan yang terdaftar di negara berkembang dan maju dengan sistem hukum yang berbeda, sedangkan penelitian ini berfokus pada negara yang tergabung di IMS-GT dan memiliki sistem hukum yang sama yaitu common law.

\section{Pengaruh Faktor Budaya terhadap e-CTI}

Hasil pengujian membuktikan faktor budaya tidak berpengaruh terhadap e-CTI sehingga $\mathrm{H}_{4}$ ditolak. Hasil penelitian ini sama dengan penelitian Jaggi \& Low (2000). Jaggi \& Low (2000) mengatakan bahwa pengungkapan laporan keuangan di negara-negara common lawlebih dipengaruhi oleh permintaan informasi daripada dipengaruhi oleh nilai-nilai budaya. Dengan demikian, nilainilai budaya tidak memiliki pengaruh pada pengungkapan keuangan di negara-negara common law. Ketiga negara dalam penelitian ini yaitu Indonesia, Malaysia dan Singapura menggunakan sistem hukum common law sehingga menyebabkan faktor budaya menjadi tidak memiliki pengaruh terhadap e-CTI. Perbedaan penelitian ini dengan Jaggi \& Low (2000) adalah adanya kebaruan data dan perbedaan perhitungan nilai budaya.

\section{Pengaruh Ukuran Dewan Direksi terhadap e-CTI}

Hasil pengujian membuktikan ukuran dewan direksi berpengaruh positif pada e-CTI sehingga $\mathrm{H}_{5}$ diterima. Hasil penelitian ini sama dengan penelitian Akhtaruddin, et al., (2009) dan Abdillah (2015). Gandia (2008) menjelaskan bahwa semakin banyak dewan direksi perusahaan, maka fungsi pengawasan dewan direksi pada manajemen semakin meningkat. Hal ini dapat menyebabkan peningkatan tanggung jawab manajemen perusahaan kepada kepada pemegang saham. Tugas dan tanggung jawab dewan direksi yang diatur dalam POJK No. 33/POJK.04/2014 (Indonesia), Malaysian Code on Corporate Governance (Malaysia) dan Code of Corporate Governance (Singapura) menyatakan hal yang sama yaitu dewan direksi bertanggungjawab untuk kepentingan perusahaan dan para pemangku kepentingan lainnya (shareholders). Berdasarkan ketiga peraturan ini, semakin banyaknya dewan direksi perusahaan akan menyebabkan peningkatan transparansi perusahaan bagi para investor. Salah satu cara yang dapat dilakukan oleh dewan direksi untuk melaksanakan tugas dan tanggungjawab adalah dengan pengungkapan melalui internet (e-CTI). Perbedaan penelitian ini dengan Akhtaruddin, et al. (2009) dan Abdillah (2015) adalah jumlah sampel yang hanya diambil di salah satu negara. Akhtaruddin, et al. (2009) melakukan penelitian di Malaysia sedangkan Abdillah (2015) hanya menggunakan sampel perusahaan yang ada di Indonesia.

\section{Pengaruh Proporsi Direktur Independen terhadap e-CTI}

Hasil uji regresi membuktikan proporsi direktur independen tidak berpengaruh pada e-CTI sehingga $\mathrm{H}_{6}$ ditolak. Hasil penelitian ini sama dengan penelitian dari Turrent \& Ariza (2012) dan Anggraita \& Syafiqurrahman (2013) yang menemukan bahwa terdapat pengaruh proporsi direktur independent pada e-CTI. Puspitaningrum \& Atmini (2012) mengatakan bahwa pemilihan direktur independen di Indonesia tidak berdasarkan kemampuan dan integritasnya secara individu, melainkan hanya untuk formalitas perusahaan untuk memenuhi peraturan yang ditetapkan pemerintah. Oleh karena itu, tugas dan fungsi direktur independen dalam melakukan pengawasan pada kinerja manajemen tidak berjalan dengan baik sehingga tidak memengaruhi pengungkapan informasi perusahaan. Salleh, et al. (2017) mengatakan bahwa direktur independen di Malaysia memiliki 2 tugas utama yaitu independen dari manajemen perusahaan dan independen dari pemegang saham. Peraturan direktur independen di Singapura yaitu Singapore Institutes of Directors (SGP No. 7/ 2007) mengatakan bahwa peran utama direktur independen bukan untuk melindungi kepentingan pemegang saham tetapi untuk bertindak sebagai dewan pemeriksa dan pengatur keseimbangan tindakan dewan direksi dan manajemen perusahaan. Penjelasan tersebut menggambarkan bahwa direktur independen di ketiga negara IMS-GT tidak memiliki pengaruh terhadap tingkat transparansi perusahaan karena fungsi dan tujuan pembentukan tidak fokus pada transparansi informasi keuangan ataupun non-keuangan untuk kepentingan shareholders. Penelitian ini berbeda dengan penelitian dari Turrent \& Ariza (2012) karena penelitian tersebut menggunakan sampel perusahaan yang terdaftar di negara Spanyol dan Meksiko. Sedangkan, perbedaan penelitian ini dengan penelitian Anggraita \& Syafiqurrahman (2013) adalah di penggunaan sampel perusahaan yang terdaftar di China, India dan Indonesia. 


\section{Pengaruh Pemusatan Kepemilikan terhadap e-CTI}

Hasil pengujian membuktikan pemusatan kepemilikan tidak berpengaruh pada e-CTI sehingga $\mathrm{H}_{7}$ ditolak. Hasil penelitian ini sama dengan penelitian dari Anggraita \& Syafiqurrahman (2013), Fikrisani \& Cahyonowati (2015) dan Puspitaningrum \& Atmini (2012). Novius (2019) mengatakan bahwa perusahaan yang memiliki persentase kepemilikan yang tinggi mendorong perusahaan segera melaporkan laporan keuangan karena tuntutan para pemegang saham. Namun dalam penelitian ini perusahaan dari ketiga negara yaitu Indonesia, Malaysia dan Singapura memiliki rata-rata pemusatan kepemilikan tidak lebih besar dari 50\% sehingga hal ini menyebabkan perusahaan tidak terdorong untuk melakukan pengungkapan informasi lain selain informasi keuangan di internet. Perbedaan penelitian ini dengan Anggraita \& Syafiqurrahman (2013) adalah perbedaaan sampel penelitian. Anggraita \& Syafiqurrahman (2013) menggunakan sampel penelitian perusahaan yang terdaftar di Bursa Efek China, India dan Indonesia. Sedangkan perbedaan penelitian ini dengan Puspitaningrum \& Atmini (2012) dan Fikrisani \& Cahyonowati (2015) adalah terletak pada jumlah sampel yang diambil dan penelitian hanya dilakukan di Indonesia pada tahun 2010 dan 2013.

\section{Perbedaan Tingkat e-CTI Ketiga Negara}

Hasil uji One Way ANOVA menunjukkan bahwa tingkat e-CTI dari ketiga negara yaitu Indonesia, Malaysia dan Singapura adalah identik atau tidak memiliki perbedaan signifikan sehingga $\mathrm{H}_{8}$ diterima. Tingkat e-CTI yang hampir sama disebabkan oleh adanya revolusi industri 4.0 dan kerja sama ekonomi. Revolusi industri 4.0 menyebabkan internet menjadi sarana yang tepat dan mudah bagi perusahaan dalam berkomunikasi dan mengambil kesempatan untuk menarik investor. Selain itu, kerjasama ekonomi yang dimiliki oleh ketiga negara yaitu IMS-GT menyebabkan perusahaanperusahaan dari ketiga negara tidak hanya bersaing dengan perusahaan sejenis di negara sendiri melainkan juga bersaing dengan perusahaan sejenis di negara lain. Hal ini mendorong manajemen perusahaan untuk berlomba-lomba mengembangkan perusahaan agar tidak kalah bersaing dengan perusahaan lain. Persaingan ini dilakukan untuk mendapatkan pendanaan yang besar dari investor. Revolusi industri 4.0 dan perkembangan internet yang masif memudahkan manajemen untuk mengungkapkan informasi perusahaan baik informasi keuangan maupun informasi non-keuangan. Informasi keuangan yang disajikan dalam laporan keuangan perusahaan dapat digunakan investor sebagai acuan dalam mengambil keputusan investasi yang tepat.

\section{SIMPULAN}

Penelitian ini berfokus pada pengaruh makro dan mikro ekonomi terhadap tingkat e-CTI pada negara yang tergabung dalam IMS-GT tahun 2017 dan perbedaan tingkat e-CTI pada ketiga negara. Hasil penelitian menunjukkan bahwa dari tujuh variabel yang digunakan hanya ukuran dewan direksi yang berpengaruh terhadap e-CTI. Hal ini disebabkan oleh pola pikir masyarakat di ketiga negara tentang konsumsi dan investasi, sistem common law yang digunakan serta fungsi dewan direksi dan direktur independen yang diatur oleh tiga negara. Selain itu, hasil penelitian juga menemukan bahwa tingkat e-CTI di tiga negara adalah identik. Keterbatasan dalam penelitian ini adalah kesulitan pada bahasa website perusahaan yang tidak disajikan dalam bahasa inggris atau Indonesia dan subyektivitas dalam interpretasi informasi dalam website maupun laporan tahunan perusahaan karena perbedaan format laporan tahunan masing-masing negara. Hasil penelitian dapat menjadi bahan pertimbangan investor dalam pengambilan keputusan investasi. Bagi perusahaan, hasil penelitian ini berguna dalam pengambilan keputusan berkaitan dengan tingkat transparansi perusahaan. Selain itu, hasil penelitian juga menunjukkan bahwa minat investor pada negara yang tergabung dalam IMS-GT ini tidak dipengaruhi faktor makro karena investor lebih mempertimbangkan kondisi mikro ekonomi. Selain itu, ketiga negara masih termasuk dalam negara berkembang. Penelitian selanjutnya diharapkan dapat mempertimbangkan penggunaan faktor makro lain dan mikro serta pengukuran kedua faktor sehingga didapatkan variabel yang berpengaruh terhadap tingkat e-CTI.

\section{DAFTAR RUJUKAN}

Abdillah, M. R. (2015). Pengaruh Karakteristik Dewan Komisaris Terhadap Pengungkapan Internet Financial Reporting (IFR). Dinamika Ekonomi Jurnal Ekonomi dan Bisnis, 8(1), 53-70.

Agoes, S. \& Ardana, I. C. (2014). Etika Bisnis dan Profesi. Jakarta: Salemba Empat.

Akhtaruddin, M., Hossain, M. A., Hossain, M., \& Yao, L. (2009). Corporate Governance and Voluntary Disclosure in Corporate Annual Reports of Malaysian Listed Firms. Journal of Applied Management Accounting and Research, 71), 1-20. doi:10.22495/cbv8i1art4. 
Anggraita, V. F. \& Syafiqurrahman, M. (2013). Transparansi Informasi Perusahaan Berbasis Internet (e-CTI) pada Perusahaan yang Terdaftar di China (SSE50), India (NIFTY), dan Indonesia (LQ45). Simposium Nasional Akuntansi XVI, 514-538. Manado.

Archambault, J. J. \& Archambault, M. E. (2003). A Multinational Test of Determinants of Corporate Disclosure. The International Journal of Accounting, 38, 173-194. doi:10.1016/S0020-7063(03)000219.

Askary, S., Punder, J. S., \& Yazdifar, H. (2008). Influence of Culture on Accounting Uniformity among Arabic Nations. Education, Business, and Society: Contemporary Middle Eastern Issues, 1(2), 145154. doi:10.1108/17537980810890329.

BKPM. (2017). Inilah 10 Negara dengan Investasi Terbesasr di Indonesia. https://databoks.katadata.co.id. 1 Desember 2017 (15:30).

Boediono. (1985). Teori Pertumbuhan Ekonomi. Yogyakarta: BPFE.

Bonson, E. \& Escobar, T. (2002). A Survey on Voluntary Disclosure on the Internet. Empirical Evidence from 300 European Union Comapnies. The International Journal of Digital Accounting Research, 2(1), 27-51. doi:10.4192/1577-8517-v2_2.

Breliastiti, R. \& Giam, H. S. (2015). Pengaruh Ukuran Perusahaan, Leverage, dan Tipe Industri Terhadap Corporate Information Transparency on The Internet (e-CTI) Perusahaan LQ45. Jurnal Akuntansi Bisnis, $8(2), 1-31$.

Cahyono, Y. T. (2003). Pengaruh Inflasi terhadap Pelaporan Keuangan. Jurnal Akuntansi dan Keuangan, 2(2), 141-150. doi:10.23917/reaksi.v212.3695.

Campbell,J. L. (2006). Institutional Analysis and The Paradox of Corporate Social Responsibility. American Behavioral Scientist, 497), 925-938. doi:10.1177/0002764205285172.

Chaudhuri, S. \& Mukhopadhyay, U. (2014). Foreign Direct Investment in Developing Countries: a Theoretical Evaluation. New York: Spinger.

Elfeky, M. I. (2017). The Extent of Voluntary Disclosure and Its Determinants in Emerging Markets: Evidence From Egypt. The Journal of Finance and Data Science, 3(1), 45-59. doi:10.1016/j.jfds.2017.09.005.

Erer, M., \& Dalgic, O. M. (2011). The Impact of Corporate Governance on Internet Financial Reporting: Evidence from Turkey. International Journal of Business Research, 11(3). doi:10.1504/ IJIBS.2017.085176.

Fikrisani, M. \& Cahyonowati, N. (2015). Analisis Faktor Yang Mempengaruhi Tingkat Pengungkapan Internet Corporate Reporting. Diponegoro Journal of Accounting, 4(3), 1-10.

Friedman, M. L. (1969). The Legal System: A Social Science Perspective. New York: Russel Soge Foundation.

Gandia, J. L. (2008). Determinants of Internet - Based Corporate Governance Disclosure by Spanish Listed Companies. Online Information Review, 32(6), 791-817. doi:10.1108/14684520810923944.

Harsono, M. (2002). Prosedur Pengujian Variabel Kontrol dan Moderator Dalam Penelitian Perilaku Dengan Menggunakan SPSS 10.00. Surakarta: Universitas Sebelas Maret.

Hashim, A. H. (2012). The Influence of Culture on Financial Reporting Quality in Malaysia. Asian Social Science, \&(13), 192-200. doi:10.5539/ass.v8n13p192.

Hofstede, G., Hofstede, G. J., \& Minkov, M. (2010). Cultures and Organizations: Software of the Mind. New York: Mc Graw Hill.

Holthausen, R. W. (2009). Accounting Standards, Financial Reporting Outcomes, and Enforcement. Journal of Accounting Research, 472), 447-458. doi:10.1111/j.1475-679X.2009.00330.

Idris, M. (2020). Singapura Pernah Tolak Label Sebagai Negara Maju di WTO. https://money.kompas. com. 24 Februari 2020 (08:20).

Jaggi, B., \& Low, P. (n.d.). Impact of Culture, Market Forces, and Legal System on Financial Disclosures. The International Journal of Accounting; 35(4), 495-519. doi:10.1016/S0020-7063(00)00076-5

Kasmir. (2012). Analisis Laporan Keuangan. Jakarta: Raja Grafindo.

Kieso, E., Weygandt, J. J., \& Warfield, T. D. (2017). Akuntansi Keuangan Menengah (Intermediate Accounting) (Edisi IFRS). Jakarta: Salemba Empat. 
Lington, R. (1984). Antropologi: Suatu Penyelidikan Tentang Manusia. Bandung: Jemars.

Mir, M. Z., Chatterjee, B., \& Rahaman, A. S. (2009). Culture and corporate voluntary reporting: A comparative exploration of the chairperson's report in India and New Zealand. Managerial Auditing Journal, 24(7), 639-667. doi:10.1108/02686900910975369.

Munawir, S. (2015). Analisis Laporan Keuangan. Jakarta: Salemba Empat.

Normala, A. (2018). Indonesia Attracts Foreign Direct Investments. https://jakartaglobe.id. 31 Januari 2018 (13.14).

Novius, A. (2019). Faktor-Faktor yang Mempengaruhi Ketepatan Waktu Corporate Internet Reporting dalam Mendukung Transparansi Keuangan pada Perusahaan yang Terdaftar di Bursa Efek Indonesia. Fokus Ekonomi: Jurnal Ilmiah Ekonomi, 14(1), 59-78. doi:10.34152/fe.14.1.59-78.

Nur, E. M. (2012). Konsumsi dan Inflasi Indonesia. Jurnal Kajian Ekonomi, 1(1), 55-77.

Nurfadilah, W. \& Sagara, Y. (2015). Pengaruh Good Corporate Governance, Karakteristik Perusahaan dan Regulasi Pemerintah Terhadap Pengungkapan Corporate Social Responsibility. Akuntabilitas, \&(1), 78-89. doi: 10.15408/akt.v8i1.2763.

Ojah, K. \& Mokoteli, T. M. (2012). Internet Financial Reporting, Infrastructures and Corporate Governance: An International Analysis. Review of Development Finance, 2(2), 69-83.

Othman, R., Thani, A. M., \& Ghani, E. K. (2009). Determinants of Islamic Social Reporting among Top Shariah-Approved Companies in Bursa Malaysia. Research Journal of International Studies, 12(10), 4-20.

Ousama, A. A., \& Fatimah, A. H. (2010). Factors Influencing Voluntary Disclosure: Empirical Evidence from Shariah Approved Companies. Malaysian Accounting Review, 9(1), 85-103. doi:10.24191/mar. v9i1.247.

Puspitaningrum, D. \& Atmini, S. (2012). Corporate Governance Mechanism and the Level of Internet Financial Reporting: Evidence from Indonesian Companies. Procedia Economics and Finance, 2, 157-166. doi:10.1016/S2212-5671(12)00075.

Salleh, K., Hamid, N. A., Harun, N., Bidin, A., \& Ghadas, Z. A. (2017). The Independent Directors in Malaysia: The Analysis of the Legal Requirement for Conventional and Shariah Business Companies. World Applied Sciences Journal, 3599), 1737-1741. doi:10.5829/idosi.wasj.2017.1737.1741.

Samaha, K. \& Abdallah, S. (2011). Further Evidence on Web-based Corporate Dosclosures in Developed Versus Developing Countries: A Comparative Analysis of Nature and Determinants in Egypt and The United Kingdom. International Journal of Disclosure and Governance, 9(2), 148-180.

Schumpeter, J. (1934). The Theory of Economic Development. An Inquiry into Profits, Capital, Credit, Interest and the Business Cycle. Massachusetts: Harvard.

Sukirno, S. (2013). Makro Ekonomi, Teori Pengantar. Jakarta: PT. Raja Grafindo Persada.

Suwardjono. (2014). Teori Akuntansi Perekayasaan Pelaporan Keuangan (3 ed.). Yogyakarta: BPFE.

Taman, A. \& Nugroho, B. A. (2012). Determinan Kualitas Implementasi Corporate Governance pada Perusahaan yang terdaftar di Bursa Efek Indonesia periode 2004-2008. Jurnal Pendidikan Akuntansi Indonesia, 9, 1. doi:10.21831/jpai.v9i1.955.

Turrent, G. B. \& Ariza, L. R. (2012). Corporate Information Transparency on the Internet by Listed Companies in Spain (IBEX35) and Mexico (IPYC). The International, 12, 1-37.

Utomo, B. (2009). Geografi Membuka Cakrawala Dunia 3. Jakarta: Pusat Perbukuan Departemen Pendidikan Nasional.

Wiwin. (2017). Studi Corporate Information Transparency on The Internet (e-CTI) pada Bursa Efek Thailand, Singapura, Malaysia, dan Indonesia. Parsimonia, 3(3), 68-87.

Zarkasyi, M. W. (2008). Good Corporate Governance pada Badan Usaha Manufaktur, Perbankan, dan Jasa Keuangan Lainnya. Bandung: Alfabeta. 